\title{
Profiling Metal Oxides with Lipids: Magnetic Liposomal Nanoparticles Displaying DNA and Proteins
}

\author{
Feng Wang, ${ }^{[a, b]}$ Xiaohan Zhang, ${ }^{[b]}$ Yibo Liu, ${ }^{[b]}$ Zhi Yuan (William) Lin, ${ }^{[b]}$ Biwu Liu, ${ }^{[b]}$ and Juewen Liu*[b]
}

\begin{abstract}
Metal oxides include many important materials with various surface properties. For biomedical and analytical applications, it is desirable to engineer their biocompatible interfaces. Herein, a phosphocholine liposome (DOPC) and its headgroup dipole flipped counterpart (DOCP) are mixed with ten common oxides. Using the calcein leakage assay, cryo-TEM, and $\zeta$-potential measurement, these oxides are grouped into three types. The type 1 oxides $\left(\mathrm{Fe}_{3} \mathrm{O}_{4}\right.$, $\mathrm{TiO}_{2}, \mathrm{ZrO}_{2}, \mathrm{Y}_{2} \mathrm{O}_{3}, I T O, \mathrm{In}_{2} \mathrm{O}_{3}$, and $\mathrm{Mn}_{2} \mathrm{O}_{3}$ ) form supported bilayers only with DOCP. The type $2\left(\mathrm{SiO}_{2}\right)$ forms supported bilayers only with DOPC. The type 3 ( $\mathrm{ZnO}$ and $\mathrm{NiO}$ ) are cationic and they damage lipid membranes. Magnetic $\mathrm{Fe}_{3} \mathrm{O}_{4}$ nanoparticles are further studied for conjugation of fluorophores, proteins and DNA to the supported DOCP bilayers via lipid headgroup labeling, covalent linking, or lipid insertion. Delivery of the conjugates to cells and selectively DNA hybridization are demonstrated. This work provides a general solution for coating the type 1 oxides with a simple mixing in water, facilitating applications in biosensing, separation, and nanomedicine.
\end{abstract}

Mimicking the cell structure, enveloping nanomaterials with a lipid bilayer is a unique way to increase biocompatibility. ${ }^{[1]}$ The supported lipid bilayer masks the underlying inorganic core, allowing different materials to have a common biointerface. Upon this lipid coating, various ligands such as aptamers, peptides and antibodies can be readily conjugated. ${ }^{[2]}$ Furthermore, lipid bilayers are fluid, allowing dynamic organization of surface ligands for optimal polyvalent binding. ${ }^{[3]} \mathrm{A}$ primary example is coating silica by phosphocholine lipids (PC). ${ }^{[4]}$ The PC headgroup contains a negatively charged phosphate and a positively charged choline (Figure 1A), rendering this zwitterionic lipid overall charge neutral.

Such simple PC lipid wrapping however does not occur on most other oxides, which encompass a diverse range of useful materials. A particularly important example is magnetic iron oxide, ${ }^{[5-7]}$ which is widely used for drug delivery, imaging, biosensing and separation. ${ }^{[8-15]}$ To attach biomolecules to iron oxide, its surface needs to be first coated with hydrophobic ligands, carbon, or silica. ${ }^{[10,11,16,17]}$ Efforts have also been made to coat lipid membranes. For example, De Cuyper et al enveloped a phosphatidylglycerol (PG) bilayer on iron oxide, but the process takes 2 days of dialysis and ligand exchange. ${ }^{[18,19]}$ Beyond iron oxide, there are many other important oxides. Thus, a general

\footnotetext{
[a] Dr. F. Wang

School of Biological and Medical Engineering, Hefei University of Technology, Hefei, Anhui 230009, China

[b] Dr. F. Wang, X. Zhang, Y. Liu, Z. Lin, B. Liu, Prof. Dr. J. Liu Department of Chemistry, Waterloo Institute for Nanotechnology University of Waterloo, Waterloo, Ontario, Canada, N2L 3G1 E-mail: liujw@uwaterloo.ca
}

Supporting information for this article can be found under: http://dx.doi.org/. procedure for their lipid coating and an understanding of their biointerfaces is of highly practical and fundamental importance.

Flipping the PC headgroup dipole produces a choline phosphate (DOCP, Figure 1B). ${ }^{[20]}$ This chemistry was recently used as a general adherent for cell membranes. ${ }^{[21]}$ Herein, we compare ten common oxides by using DOPC and DOCP, and report a simple method for preparing lipid-enveloped oxide nanoparticles (NPs) in aqueous buffers and their bioconjugation.

To have a complete understanding, ten common oxide NPs $\left(\mathrm{SiO}_{2}, \mathrm{Fe}_{3} \mathrm{O}_{4}, \mathrm{TiO}_{2}, \mathrm{ZrO}_{2}, \mathrm{Y}_{2} \mathrm{O}_{3}, \mathrm{ZnO}, \mathrm{NiO}, \mathrm{In}_{2} \mathrm{O}_{3}, \mathrm{ITO}\right.$, and $\left.\mathrm{Mn}_{2} \mathrm{O}_{3}\right)$ were included in this study. These NPs were extensively washed to ensure a clean native oxide surface. Their TEM micrographs are shown in Figure $\mathrm{S} 1$ and most NPs are below $50 \mathrm{~nm}$ (Figure S2). Our liposomes were prepared by extrusion with an average size of $\sim 100 \mathrm{~nm}$ (Figure S3A). DOPC is nearly charge neutral, while DOCP is anionic due to an extra charge on the terminal phosphate (Figure S3B). Using rhodamine (Rh)-labeled liposomes, we confirmed that all these oxide NPs can adsorb these two liposomes (Figure S4).

After adsorption, the liposomes may further break and wrap the oxides to form supported bilayers, and we are most interested in these cases. To probe liposome breakage, a calcein leakage assay was performed. Inside each liposome, the calcein concentration was $\sim 100 \mathrm{mM}$, leading to self-quenched fluorescence. Fluorescence enhancement would then indicate calcein leakage and compromised membrane integrity. For each experiment, the background fluorescence was monitored for 5 min before an oxide NP was added. In the end, Triton X-100 was added to fully rupture the liposome to calculate the extent of oxide-induced leakage.

Seven oxides $\left(\mathrm{Fe}_{3} \mathrm{O}_{4}, \mathrm{TiO}_{2}, \mathrm{ZrO}_{2}, \mathrm{Y}_{2} \mathrm{O}_{3}, \mathrm{ITO}, \mathrm{In}_{2} \mathrm{O}_{3}\right.$ and $\mathrm{Mn}_{2} \mathrm{O}_{3}$ ) leaked the DOCP liposome but not DOPC (Figure 2A). $\mathrm{SiO}_{2}$ is the only one that leaked DOPC but not DOCP (Figure 2B). Finally, $\mathrm{ZnO}$ and $\mathrm{NiO}$ leaked both liposomes (Figure 2C). In most cases, liposomes only leaked partially by the oxides, which may be related to the different surface area and surface properties of the oxides. For this initial study, we are more concerned with whether leakage occurs rather than the extent of leakage.

To confirm a clean surface, we also freshly prepared $\mathrm{Fe}_{3} \mathrm{O}_{4}$ NPs in our own lab and they indeed showed a similar leakage profile (Figure S5). In a separate test, we intentionally capped $\mathrm{Fe}_{3} \mathrm{O}_{4}$ using citrate to mimic surface contaminated NPs (Figure $\mathrm{S} 6)$. In this case, a completely different profile was observed with an induction period that can be attributed to the displacement of the surface citrate by the DOCP liposomes, which in turn confirms that our NPs were not capped by strong ligands.

The leakage experiments suggest that the DOCP liposome might break on many oxides. However, other processes may also cause leakage such as local pore formation or even full membrane disruption. To further understand this, we carried out cryo-TEM experiment for a few representative oxides. 
For the seven oxides in Figure 2A, we chose to study $\mathrm{Fe}_{3} \mathrm{O}_{4}$ since it is important for many applications and is the focus of this study. We could not find any intact DOCP liposomes (Figure 1F); instead, a $\sim 5 \mathrm{~nm}$ lipid bilayer feature was observed around each $\mathrm{Fe}_{3} \mathrm{O}_{4} \mathrm{NP}$, confirming supported bilayers and explaining the above calcein leakage data. In sharp contrast, DOPC was adsorbed as intact liposomes (Figure $1 \mathrm{G}$ ), ${ }^{[5]}$ which is also consistent with its lack of calcein leakage. Their larger area cryoTEM micrographs are shown in Figure S7-S8. A cartoon describing their interactions is presented in Figure 1C.<smiles>CCCCCCCCCCCCC=CCCCCCCCCCCCC(=O)OC[C@H](COP(=O)(O)OCC[N+](C)(C)C)OC(=O)CCCCCCCC</smiles>

C

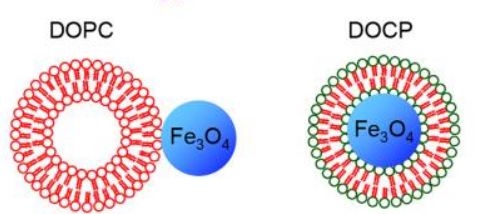

Also include $\mathrm{TiO}_{2}, \mathrm{ZrO}_{2}, \mathrm{Y}_{2} \mathrm{O}_{3}, \mathrm{ITO}, \mathrm{In}_{2} \mathrm{O}_{3}$, and $\mathrm{Mn}_{2} \mathrm{O}_{3}$

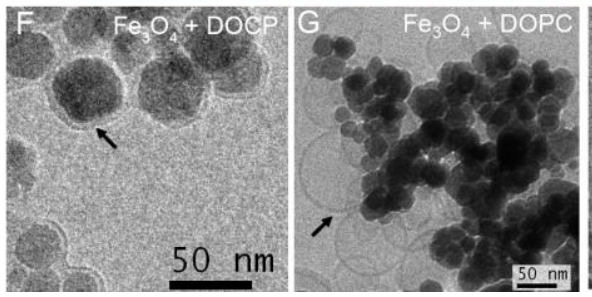

D

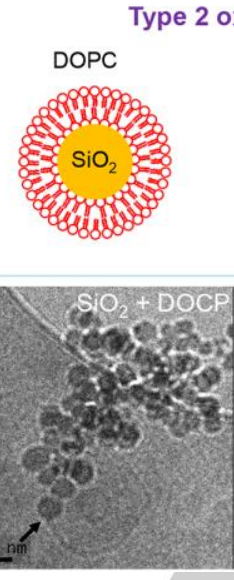

B
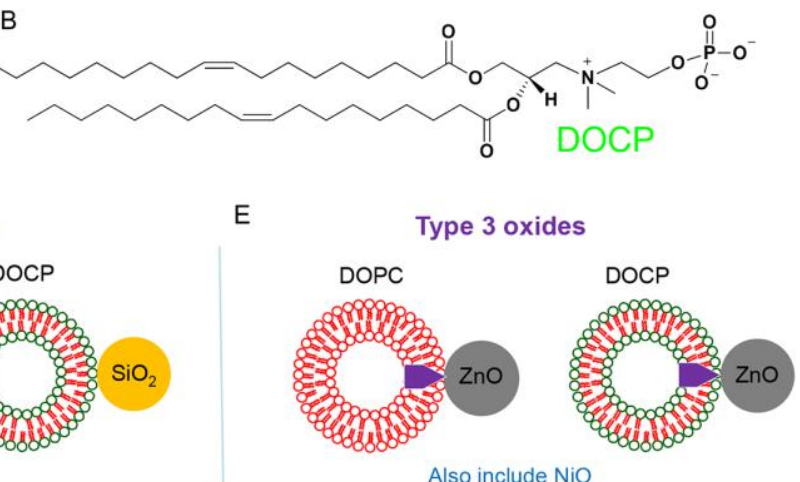

Figure 1. The structures of (A) DOPC and (B) DOCP lipids. The three types of metal oxides based on their lipid interactions: (C) Type 1 includes $\mathrm{Fe}_{3} \mathrm{O}_{4}, \mathrm{TiO}_{2}, \mathrm{ZrO}_{2}, \mathrm{Y}_{2} \mathrm{O}_{3}$, ITO, $\mathrm{In}_{2} \mathrm{O}_{3}$, and $\mathrm{Mn}_{2} \mathrm{O}_{3}$; they are adsorbed by DOPC, but form supported bilayers with DOCP. (D) Type 2 includes only $\mathrm{SiO}_{2}$, forming supported bilayers with DOPC. (E) Type 3 includes cationic $\mathrm{ZnO}$ and $\mathrm{NiO}$, damaging the membranes (pores indicated by the purple color); full membrane disruption occurs to DOCP when mixed with $\mathrm{ZnO}$. Cryo-TEM micrographs of $(\mathrm{F}, \mathrm{G}) \mathrm{Fe}_{3} \mathrm{O}_{4},(\mathrm{H}, \mathrm{I}) \mathrm{SiO}_{2}$, and $(\mathrm{J}, \mathrm{K})$ ZnO NPs mixed with ( $F, H, J)$ DOCP or (G, I, K) DOPC liposomes. In each sample, the liposomes were added in excess and the free liposomes were removed after centrifugation and washing before cryo-TEM; see SI for detail. The arrowheads point at the lipid features.
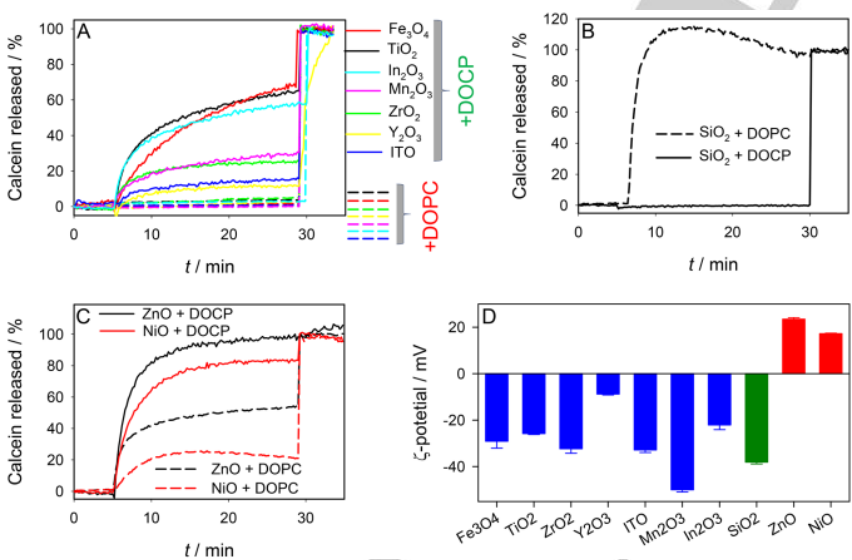

Figure 2. Calcein leakage from the DOPC and DOCP liposomes induced by adding (A) $\mathrm{Fe}_{3} \mathrm{O}_{4}, \mathrm{TiO}_{2}, \mathrm{ZrO}_{2}, \mathrm{Y}_{2} \mathrm{O}_{3}, \mathrm{ITO}, \mathrm{In}_{2} \mathrm{O}_{3}$, or $\mathrm{Mn}_{2} \mathrm{O}_{3}$. (B) $\mathrm{SiO}_{2}$; and (C) $\mathrm{ZnO}$ and $\mathrm{NiO}$ NPs. Solid lines: mixed with DOCP; dashed lines: mixed with DOPC. Oxides were added at $5 \mathrm{~min}$ and Triton X-100 at $30 \mathrm{~min}$ in buffer (10 mM HEPES, pH 7.4 with $100 \mathrm{mM}$ $\mathrm{NaCl}$ ), except for $\mathrm{In}_{2} \mathrm{O}_{3}$, ITO, $\mathrm{Mn}_{2} \mathrm{O}_{3}$ with $300 \mathrm{mM} \mathrm{NaCl}$. (D) $\zeta$-potential of the oxides in $10 \mathrm{mM} \mathrm{HEPES}, \mathrm{pH} 7.4$ at $25^{\circ} \mathrm{C}$.
$\mathrm{SiO}_{2}$ leaked DOPC but not DOCP (Figure 2B). It is poorly adsorbed by DOCP liposomes (Figure $1 \mathrm{H}$ ), while DOPC formed supported bilayers on $\mathrm{SiO}_{2}$ (Figure 1I). ${ }^{[5,22]}$ This is exactly opposite to the oxides in Figure 2A (see Figure 1D for schematics). This cryo-TEM data can also explain the calcein leakage profile for $\mathrm{SiO}_{2}$. For the two oxides in Figure $2 \mathrm{C}$, we picked $\mathrm{ZnO}$ for its biomedical and optical importance. Interestingly, we observed 'intact' spherical DOPC liposomes (Figure 1K), suggesting the leakage observed in Figure $2 \mathrm{C}$ was due to local pore formation at the interface. Different from the other tested oxides, which are negatively charged at neutral $\mathrm{pH}, \mathrm{ZnO}$ and $\mathrm{NiO}$ are positively charged (Figure 2D). Many cationic materials induce defects in $\mathrm{PC}$ lipid bilayers, ${ }^{[23]}$ and this might explain the leakage by $\mathrm{ZnO}$ without full liposome disruption. Quite surprisingly, we cannot find any intact DOCP liposomes when it was mixed with $\mathrm{ZnO}$ (Figure $1 \mathrm{~J})$. At the same time, the $\mathrm{ZnO}$ surface had no lipid coating, while $\mathrm{ZnO}$ induced full DOCP leakage (Figure $2 \mathrm{C}$ ). Taken together, we attribute this to the strong interaction between $\mathrm{ZnO}$ and the DOCP phosphate group, which fully disrupted the lipid membrane.

Based on the calcein leakage, cryo-TEM and $\zeta$-potential data, we grouped these oxides into three types (Figure 1C-E). We also rationalize the grouping based on their surface properties. The seven type 1 oxides are all negatively charged and this is also consistent with their point of zero charge (PZC) reported in the 
literature (Table S1). ${ }^{[24]}$ All these oxides are likely to interact with the liposomes through the lipid phosphate group. ${ }^{[5,7,25]}$ While both DOPC and DOCP have a phosphate, DOCP has a directly exposed phosphate that is not hindered by the choline group to allow full liposome wrapping.

The type 2 includes only $\mathrm{SiO}_{2}$, which leaked DOPC but not DOCP. While $\mathrm{SiO}_{2}$ is also negatively charged, it has the lowest $P Z C$ value of $<2$, which make phosphate binding very unfavorable at neutral $\mathrm{pH}$. This might be a reason that silica uses mainly van der Waals force for lipid interaction. ${ }^{26]}$ The special surface property of $\mathrm{SiO}_{2}$ was noticed previously in the context of its strong surface acidity attributable to its bond strength to bond length ratio. ${ }^{[27]}$ The type 3 oxides include positively charged $\mathrm{ZnO}$ and $\mathrm{NiO} .{ }^{[28]}$ They leaked both liposomes by membrane damage. Therefore, type 3 oxides might be more toxic to cells. Among these, the type 1 and 2 oxides are the most useful candidates for preparing supporting bilayers.

An inorganic core supporting a conformal bilayer membrane is a very useful construct. ${ }^{[1]}$ We next optimized the buffer conditions for the liposome wrapping reaction using $\mathrm{Fe}_{3} \mathrm{O}_{4}$. Both $\mathrm{Fe}_{3} \mathrm{O}_{4}$ and DOCP liposomes are negatively charged at neutral $\mathrm{pH}$, and we found that liposome wrapping was promoted at higher salt concentration, lower $\mathrm{pH}$, while temperature has almost no effect from 25 to $45{ }^{\circ} \mathrm{C}$ (Figure S9A-C). We proposed that the lipid phosphate is responsible for DOCP liposome wrapping, and this is supported by that free inorganic phosphate has an inhibition effect on calcein leakage (Figure S9D). This is explained by the free phosphate capping the particle surface, thus competitively inhibiting DOCP liposome adsorption. Most previous work used hydrophobic ligands to cap magnetic NPs, and a phase transfer or ligand exchange reaction was required to bring the particles to the aqueous phase. ${ }^{[11,18,29-32]}$ Here, all the operations are carried out in an aqueous solution with a simple mixing step.

In the above work, we have profiled the oxides based on their lipid interactions, and established a general method to coat the type 1 oxides with a lipid bilayer. In addition, important insights regarding surface charge and chemical interactions were obtained. With a lipid envelope, many applications are possible.

In this initial study, we demonstrate bioconjugation on $\mathrm{Fe}_{3} \mathrm{O}_{4}$ and cellular uptake. We first tested cellular uptake using $\mathrm{Fe}_{3} \mathrm{O}_{4}$ NPs mixed with DOPC (Figure 3B) and DOCP (Figure 3C). Both liposomes contained $1 \% \mathrm{Rh}$ label, and these labeled lipids can be directly incorporated during liposome preparation (Figure 3A, reaction 1). The DOCP conjugate showed much better cellular uptake. Compared to the normal PC lipid, the CP headgroup has a flipped dipole. It has been recently proposed that this flipped dipole might adhere strongly to the cell membrane, ${ }^{[21]}$ which might be a reason for its drastic uptake by cancer cells. Our quantitative ICP-MS measurement of the iron content confirmed that the DOCP coated $\mathrm{Fe}_{3} \mathrm{O}_{4}$ was internalized $\sim 60 \%$ more than the bare NP (Figure S10). The biocompatibility of these materials were also measured. The DOPC and DOCP conjugates were not much different compared to the bare $\mathrm{Fe}_{3} \mathrm{O}_{4}$ in terms of toxicity (Figure $\mathrm{S11}$ ); all were highly biocompatible.

After studying cellular uptake, we next tested bioconjugation. Attaching ligands to iron oxide is not a simple task; it often involves organic solvents or coating another inorganic layer. ${ }^{[10,11,16]}$ With a lipid coating, we can readily achieve bioconjugation. For example, we incorporated a small fraction of the MPB-PE lipid (5\%) into DOCP. Thus, molecules with a free thiol can covalently attach to the maleimide group (Figure $3 \mathrm{~A}$, reaction 2). To demonstrate this, we employed a thiolated DNA and the bovine serum albumin (BSA) protein, both containing a carboxyfluorescein (FAM) label. When these conjugates were mixed with cells, strong green fluorescence from the DNA (Figure 3D) and BSA (Figure 3E) were observed, and they co-localized with the red lipid emission from the Rh label, suggesting these molecules were carried into the cells by the supported bilayers. The free DNA or BSA cannot be internalized by the cells (Figure S12). This DNA construct is similar to the liposomal spherical nucleic acids by Mirkin and co-workers, ${ }^{[33]}$ but it contains a magnetic core that allows additional manipulation of the conjugate. Bioconjugation can also be readily achieved by direct insertion of lipid-modified molecules (Figure 3A, reaction 3). For example, we mixed the $\mathrm{Fe}_{3} \mathrm{O}_{4} / \mathrm{DOCP}$ hybrid with a cholesterol and FAM dual labeled DNA, and efficient DNA uptake was also achieved (Figure $3 F)$.
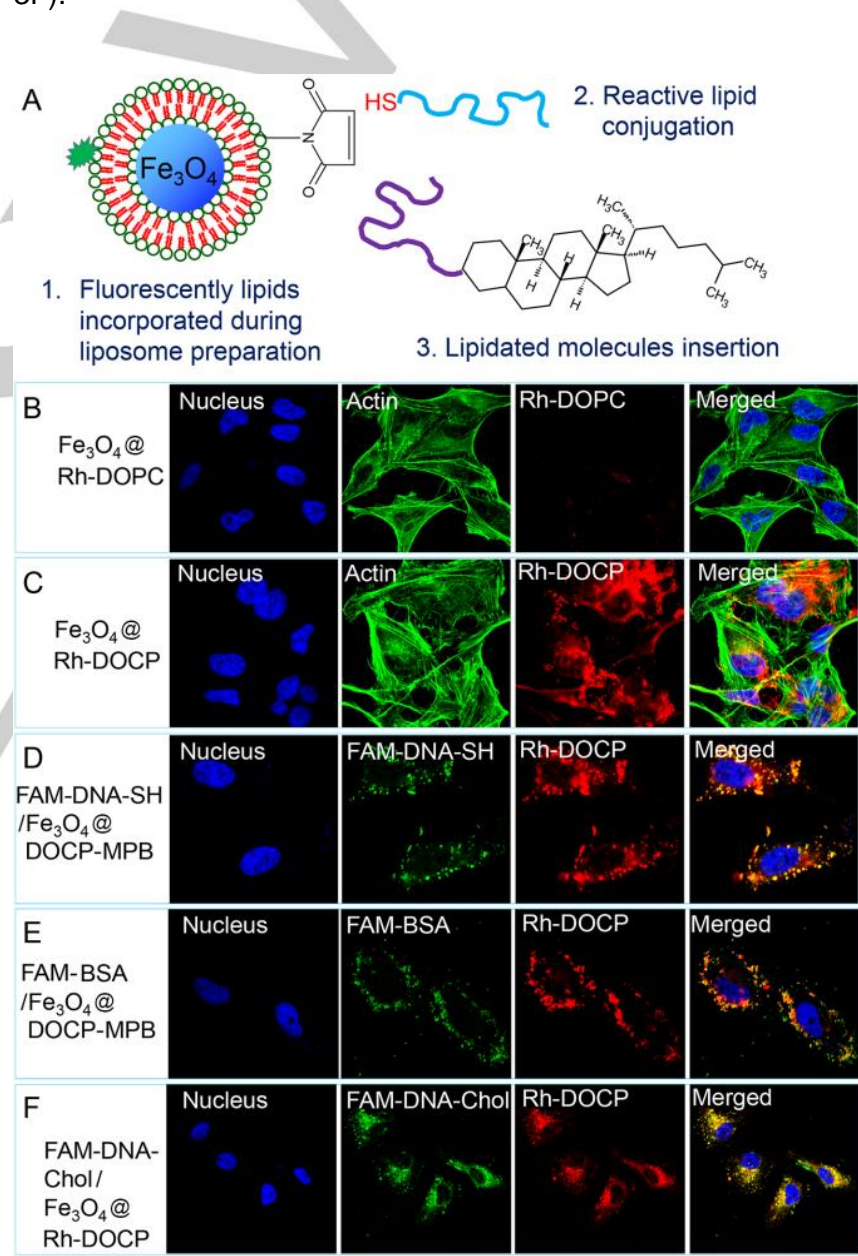

Figure 3. (A) Schematics of three methods to conjugate ligands to $\mathrm{Fe}_{3} \mathrm{O}_{4}$ NP supported DOCP bilayer. Confocal fluorescence micrographs of (B) Rh-DOPC/Fe $/ \mathrm{O}_{4}$, and (C) Rh-DOCP/Fe $3 \mathrm{O}_{4}$ internalized by HeLa cells. Internalization of (D) FAM and thiol dual labeled DNA, and (E) FAM-labeled BSA conjugated to $\mathrm{Fe}_{3} \mathrm{O}_{4}$ supported DOCP containing 5\% MPB-PE. (F) Insertion of FAM and cholesterol dual labeled DNA into the $\mathrm{Fe}_{3} \mathrm{O}_{4}$-supported DOCP membrane. Blue: cell nuclei; green: actin or FAM labels; red: $\mathrm{Rh}$ fluorescence indicating the lipids. 
The above studies only showed the conjugation reactions without using the magnetic property of the core. Finally, magnetic separation was studied. We attached a cholesterol-TEG labeled $\mathrm{A}_{15}$ DNA to the conjugate. At saturation, 600 DNAs were attached to each $30 \mathrm{~nm} \mathrm{Fe} \mathrm{O}_{4} \mathrm{NP}$ (Figure S13). These particles were then added to a solution containing a mixture of two DNA: Alexa Fluoro 647 (AF)-labeled $\mathrm{T}_{15}$ (target DNA) and a FAMlabeled random DNA (rDNA). The initial fluorescence spectra showed strong emissions from both fluorophores (Figure 4B, black lines). After adding the NPs and magnetic separation, the AF emission was significantly reduced due to its hybridization with the surface $A_{15}$, while the FAM emission was not affected (Figure $4 \mathrm{~B}$, red lines), suggesting successful DNA hybridization and magnetic separation. This experiment also indicates that DNA has maintained its molecular recognition function on the supported bilayer surface.

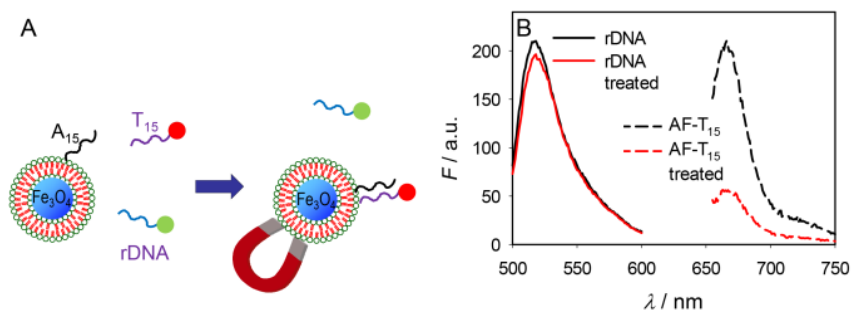

Figure 4. (A) A scheme of magnetic separation of fluorescently labeled target DNA from a mixture. (B) Fluorescence quantification of DNA separation based on the scheme in $(A)$.

In summary, this work provides a general method for capping a number of important metal oxides with an engineered lipid bilayer. We obtained a comprehensive understanding on the interaction between various oxides and $\mathrm{PC} / \mathrm{CP}$ liposomes, allowing us to classify the oxides into three types. Other than the cationic metal oxides, which damage lipid membranes, the rest can all form supported bilayers with either DOPC, or in most cases with DOCP liposomes. We further demonstrated a few applications of magnetic iron oxide NPs enabled by the lipid envelope. Further work on improving NP colloidal stability and in vivo studies with targeting ligands will prove the full potential of this hybrid material. Compared to the previously reported methods for manipulating magnetic NPs, our method requires only a simple mixing step in an aqueous buffer. This simplified operation will likely enable more researchers to use this material for a diverse range of applications.

\section{Acknowledgements}

We thank R Harris at the University of Guelph for assistance with cryo-TEM, and SJ Hu at Waterloo for assistance with ICP-MS. Funding for this work is from the Natural Sciences and Engineering Research Council of Canada (NSERC), the National Natural Science Foundation of China $(31571023,81501587)$, and Hefei University of Technology.

Keywords: Metal oxides - supported bilayers - liposomes • magnetic nanoparticles $\cdot$ phosphocholine
[1] a) J. Liu, A. Stace-Naughton, X. Jiang, C. J. Brinker, J. Am. Chem. Soc. 2009, 131, 1354-1355; b) Y. S. Tu, M. Lv, P. Xiu, T. Huynh, M. Zhang, M. Castelli, Z. R. Liu, Q. Huang, C. H. Fan, H. P. Fang, R. H. Zhou, Nat. Nanotechnol. 2013, 8, 594-601; c) W. Gao, C.-M. J. Hu, R. H. Fang, L. Zhang, J. Mater. Chem. B 2013, 1, 6569-6585; d) S. Tan, X. Li, Y. Guo, Z. Zhang, Nanoscale 2012, 5, 860-872; e) J. Liu, Langmuir 2016, 32, 4393-4404.

[2] C. E. Ashley, E. C. Carnes, G. K. Phillips, D. Padilla, P. N. Durfee, P. A. Brown, T. N. Hanna, J. Liu, B. Phillips, M. B. Carter, N. J. Carroll, X. Jiang, D. R. Dunphy, C. L. Willman, D. N. Petsev, D. G. Evans, A. N. Parikh, B. Chackerian, W. Wharton, D. S. Peabody, C. J. Brinker, Nat. Mater. 2011, 10, 389-397.

[3] a) M. Mammen, S. K. Choi, G. M. Whitesides, Angew. Chem. Int. Ed. 1998, 37, 2755-2794; Angew. Chem. 1998, 110, 2908 -2953; b) Y. Yang, J. Wang, H. Shigematsu, W. Xu, W. M. Shih, J. E. Rothman, C. Lin, Nat. Chem. 2016, 8, 476-483; c) T. D. MacDonald, T. W. Liu, G. Zheng, Angew. Chem. Int. Ed. 2014, 53, 6956-6959; Angew. Chem. 2014, 126, 7076-7079.

[4] a) E. T. Castellana, P. S. Cremer, Surf. Sci. Rep. 2006, 61, 429444; b) E. Sackmann, Science 1996, 271, 43-48; c) R. Michel, E. Kesselman, T. Plostica, D. Danino, M. Gradzielski, Angew. Chem. Int. Ed. 2014, 53, 12441-12445; Angew. Chem. 2014, 126, 12649-12653; d) A. N. Parikh, J. T. Groves, MRS Bull 2006, 31, 507-512.

[5] F. Wang, J. Liu, Small 2014, 10, 3927-3931.

[6] E. Reimhult, F. Hook, B. Kasemo, Langmuir 2003, 19, 16811691.

[7] F. Wang, J. Liu, J. Am. Chem. Soc. 2015, 137, 11736-11742.

[8] A.-H. Lu, E. L. Salabas, F. Schueth, Angew. Chem. Int. Ed. 2007, 46, 1222-1244; Angew. Chem. 2007, 119, 1242-1266.

[9] J. R. McCarthy, R. Weissleder, Adv. Drug Deliver. Rev. 2008, $60,1241-1251$.

[10] R. Hao, R. Xing, Z. Xu, Y. Hou, S. Gao, S. Sun, Adv. Mater. 2010, 22, 2729-2742.

[11] W. J. M. Mulder, G. J. Strijkers, G. A. F. van Tilborg, A. W Griffioen, K. Nicolay, NMR Biomed. 2006, 19, 142-164.

[12] J. I. Cutler, D. Zheng, X. Xu, D. A. Giljohann, C. A. Mirkin, Nano Lett. 2010, 10, 1477-1480.

[13] J. Li, C.-Y. Hong, S.-X. Wu, H. Liang, L.-P. Wang, G. Huang, X. Chen, H.-H. Yang, D. Shangguan, W. Tan, J. Am. Chem. Soc. 2015, 137, 11210-11213.

[14] Z. Li, K. Dong, S. Huang, E. Ju, Z. Liu, M. Yin, J. Ren, X. Qu, Adv. Funct. Mater. 2014, 24, 3612-3620.

[15] O. Sandre, C. Ménager, J. Prost, V. Cabuil, J. C. Bacri, A. Cebers, Phys. Rev. E 2000, 62, 3865-3870.

[16] N. A. Frey, S. Peng, K. Cheng, S. Sun, Chem. Soc. Rev. 2009 38, 2532-2542.

[17] B. Dubertret, P. Skourides, D. J. Norris, V. Noireaux, A. H. Brivanlou, A. Libchaber, Science 2002, 298, 1759-1762.

[18] M. De Cuyper, M. Joniau, Eur. Biophys. J. 1988, 15, 311-319.

[19] M. D. Cuyper, P. Müller, H. Lueken, M. Hodenius, J. Phys.: Condens. Matter 2003, 15, S1425.

[20] E. K. Perttu, A. G. Kohli, F. C. Szoka, J. Am. Chem. Soc. 2012, 134, 4485-4488.

[21] X. Yu, Z. Liu, J. Janzen, I. Chafeeva, S. Horte, W. Chen, R. K. Kainthan, J. N. Kizhakkedathu, D. E. Brooks, Nat. Mater. 2012, 11, 468-476.

[22] S. Mornet, O. Lambert, E. Duguet, A. Brisson, Nano Lett. 2005, 5, 281-285.

[23] P. R. Leroueil, S. A. Berry, K. Duthie, G. Han, V. M. Rotello, D. Q. McNerny, J. R. Baker, B. G. Orr, M. B. Banaszak Holl, Nano Lett. 2008, 8, 420-424.

[24] M. Kosmulski, J. Colloid Interf. Sci. 2002, 253, 77-87. 
[25] S. Wang, W. Morris, Y. Liu, C. M. McGuirk, Y. Zhou, J. T. Hupp, O. K. Farha, C. A. Mirkin, Angew. Chem., Int. Ed. 2015, 54, 14738-14742; Angew. Chem. 2015, 127, 14951-14955.

[26] P. S. Cremer, S. G. Boxer, J. Phys. Chem. B 1999, 103, 25542559.

[27] N. Sahai, Environ. Sci. Technol. 2002, 36, 445-452.

[28] T. Mahmood, M. T. Saddique, A. Naeem, P. Westerhoff, S. Mustafa, A. Alum, Ind. Eng. Chem. Res. 2011, 50, 10017-10023.

[29] M.-S. Martina, J.-P. Fortin, C. Ménager, O. Clément, G. Barratt, C. Grabielle-Madelmont, F. Gazeau, V. Cabuil, S. Lesieur, J. Am. Chem. Soc. 2005, 127, 10676-10685.

[30] Y. Liu, T. Chen, C. Wu, L. Qiu, R. Hu, J. Li, S. Cansiz, L. Zhang, C. Cui, G. Zhu, M. You, T. Zhang, W. Tan, J. Am. Chem. Soc. 2014, 136, 12552-12555.

[31] T. Chen, I. Öçsoy, Q. Yuan, R. Wang, M. You, Z. Zhao, E. Song, X. Zhang, W. Tan, J. Am. Chem. Soc. 2012, 134, 13164-13167.

[32] S. Tong, S. Hou, B. Ren, Z. Zheng, G. Bao, Nano Lett. 2011, 11, 3720-3726.

[33] R. J. Banga, N. Chernyak, S. P. Narayan, S. T. Nguyen, C. A. Mirkin, J. Am. Chem. Soc. 2014, 136, 9866-9869. 
Layout 2:

\section{COMMUNICATION}

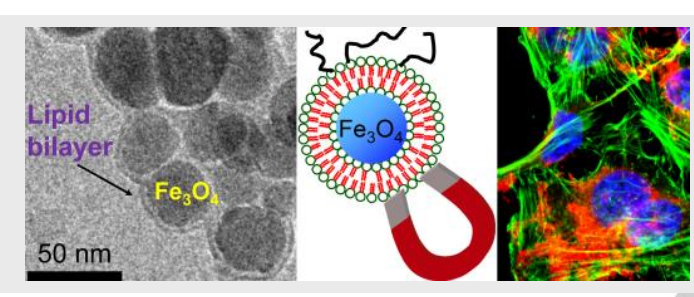

Ten common metal oxide nanoparticles are classified into three groups based on their interaction with two related liposomes. Enveloping a magnetic iron oxide core with a lipid shell facilitates bioconjugation, biocompatibility and delivery.
Author(s), Corresponding Author(s)*

Page No. - Page No.
Feng Wang, Xiaohan Zhang, Yibo Liu, Zhi Yuan (William) Lin, Biwu Liu, and Juewen Liu*

Page No. - Page No.

Profiling Metal Oxides with Lipids: Magnetic Liposomal Nanoparticles Displaying DNA and Proteins 